\title{
Mopla guttata (Acrididae: Catantopinae) rediscovered in the Western Ghats, Kerala, India
}

Dhaneesh Bhaskar ${ }^{1,2,3}$, P.S. EAsa ${ }^{1,3}$, C.H.F. Rowell ${ }^{4}$

1 Kerala Forest Research Institute, Peechi-680653 Kerala, India.

2 IUCN SSC Grasshopper Specialist Group.

3 University of Calicut, Thenhipalam, 673635-Kerala, India.

4 Zoologisches Institut, Universität Basel, Basel, Switzerland.

Corresponding author: Dhaneesh Bhaskar (dhaneeshbhaskar24@gmail.com)

Academic editor: Daniel Petit | Received 23 April 2019 | Accepted 17 June 2019 | Published 10 January 2020

http://zoobank.org/1603537E-2A31-446F-8CC4-79E333EB0F9E

Citation: Bhaskar D, Easa PS, Rowell CHF (2020) Mopla guttata (Acrididae: Catantopinae) rediscovered in the Western Ghats, Kerala, India. Journal of Orthoptera Research 29(1): 17-23. https://doi.org/10.3897/jor.29.35664

\begin{abstract}
The endemic Catantopinae genus Mopla was described by Henry in 1940 from the Malabar region of South India. Henry described two species under this genus, M. guttata and M. rubra. The female type specimens of Mopla are deposited in the Natural History Museum, London, UK. There have been no further records of these two species since their description. Seventy-six years later, the first male specimen of the genus Mopla was discovered in the Western Ghats, Kerala, India, in 2016. This paper describes the specimen, thought to be of Mopla guttata, and reconsiders its systematic placement.
\end{abstract}

\section{Keywords}

endemism, first male of genus, grasshopper, systematics, tropical forest

\section{Introduction}

Most of the 1033 known Indian grasshopper species were described by foreign researchers (Chandra et al. 2010). In modern India, grasshoppers are considered agricultural pests, hence research publications are confined to agricultural universities and regional pest research centers (Priya and Narendran 2003, Chandra et al. 2010, Nayeem and Usmani 2012). The Western Ghats region, a biodiversity hotspot, is the type locality for some endemic grasshoppers (Cigliano et al. 2018). Most of the 790 species mentioned in the Faunal Diversity in India by Tandon and Hazra (1998) are from biodiversity hotspots such as Western Ghats.

Henry (1940) collected many Catantopinae from southern India as part of a joint expedition of the British Museum and the Colombo Museum from 1936 to 1938 . He recorded the exact collection locations for future researchers and explorers; as he mentioned, this was to facilitate further work on the Orthoptera fauna of India. In Henry's (1940) publication he described some very interesting Catantopinae species including Tinnevellia andrewi, Bambusacris travancora, Siruvania dimorpha, Naraikadua charmichaelae, Palniacris maculatus, Coniocara rubropicta, Mopla guttata, and
Mopla rubra. Most of these need further investigation. However, these diversity-rich highlands were never revisited for grasshoppers after the departure of the foreign researchers. Bhaskar et al. (2018) reported 130 species of Orthoptera from the Kerala part of Western Ghats. From 2015 onwards we started searching for grasshoppers in protected areas of the State of Kerala, part of the Western Ghats. In September 2016, we came across a completely unfamiliar grasshopper in the Parambikulam Tiger Reserve (PKMTR), Kerala. Unfortunately, we have since failed to find any further specimens. Later the specimen was found to be very close to the type-specimens of Mopla that DB had photographed previously at the Natural History Museum, London, UK (NHMUK). Our male specimen was at first misidentified as Mopla rubra and illustrations were provided on the sample page of the proposed field guide to Indian Orthoptera (Bhaskar et al. 2018).

Mopla are small brachypterous catantopine grasshoppers with distinctive coloration of bright yellow stripes and spots on a dark brown background (Fig. 1). Morphologically, the genus is notable for: A) its very abbreviated frontal ridge that forms a short narrow rostrum that is lamelliformly compressed between the antennae, but becomes obsolete immediately below the antennal bases; B) the absence of visible ocelli, both medial and lateral; and C) the terminal segment of the maxillary palp is laterally expanded, forming a pale-colored broadly elliptical surface (Fig. 2). These modified palps are probably used in intraspecific communication; a similar structure is found in several other tropical forest acridid taxa, such as Ateliacris or Silvitettix.

Henry (1940) erected the genus Mopla with two species: gutta$t a$, the type of the genus, and rubra. The two species were described from two female grasshoppers from the forests of the Western Ghats Mountains of southern India, in what are now the states of Tamil Nadu and Kerala. Henry (1940) named this genus for the Muslim community inhabiting the Malabar region of South India; the Muslims of this region are locally called "Mapla" in the Malayalam language of Kerala. The type specimen of Mopla guttata was collected from Top Slip, Anamalai Tiger Reserve, Tamil Nadu, and that of Mopla rubra was collected from Nilambur, Kerala. To our 


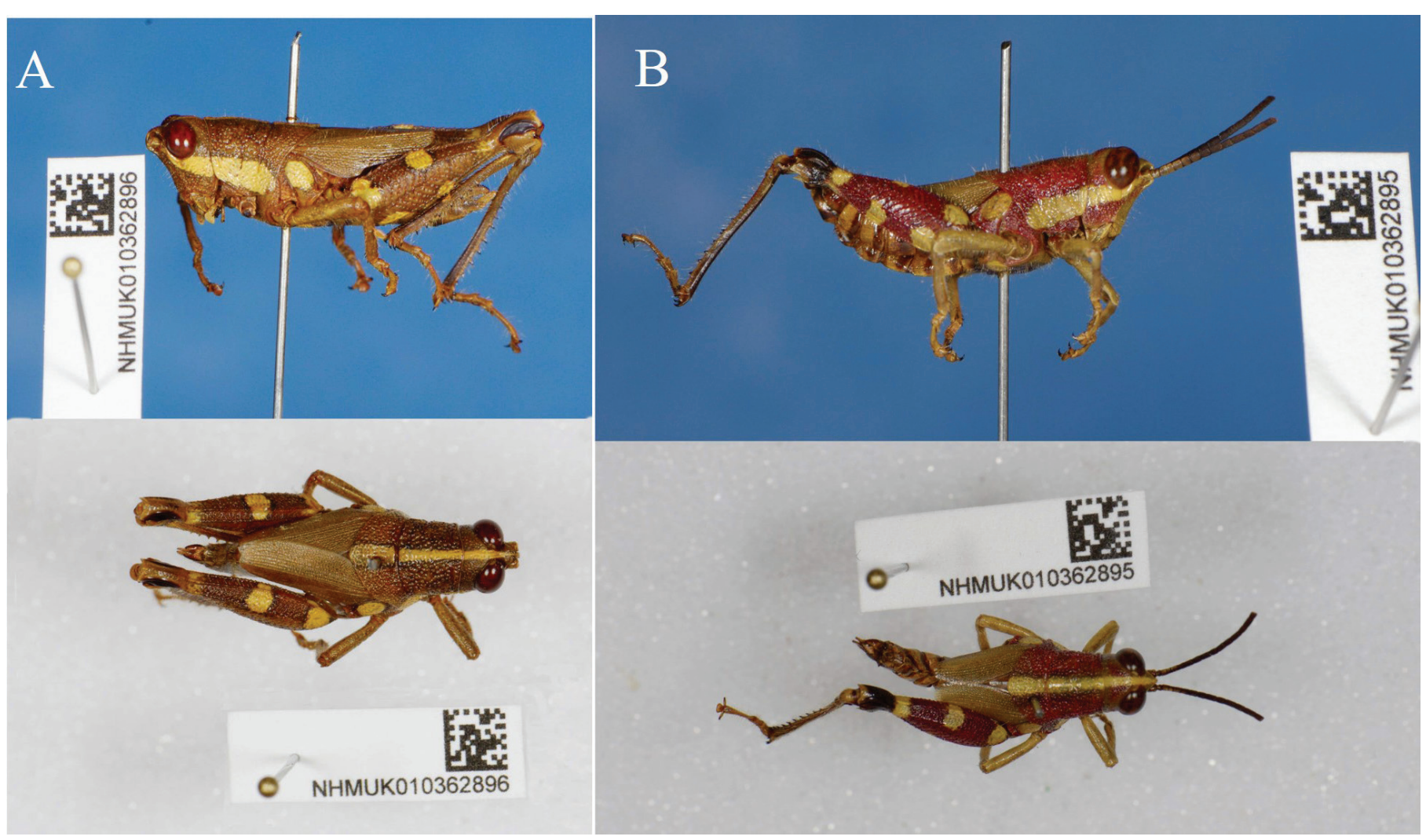

Fig. 1. A. Mopla guttata, holotype female (NHMUK); B. Mopla rubra, holotype female (NHMUK). Photo credit: D. Bhaskar.

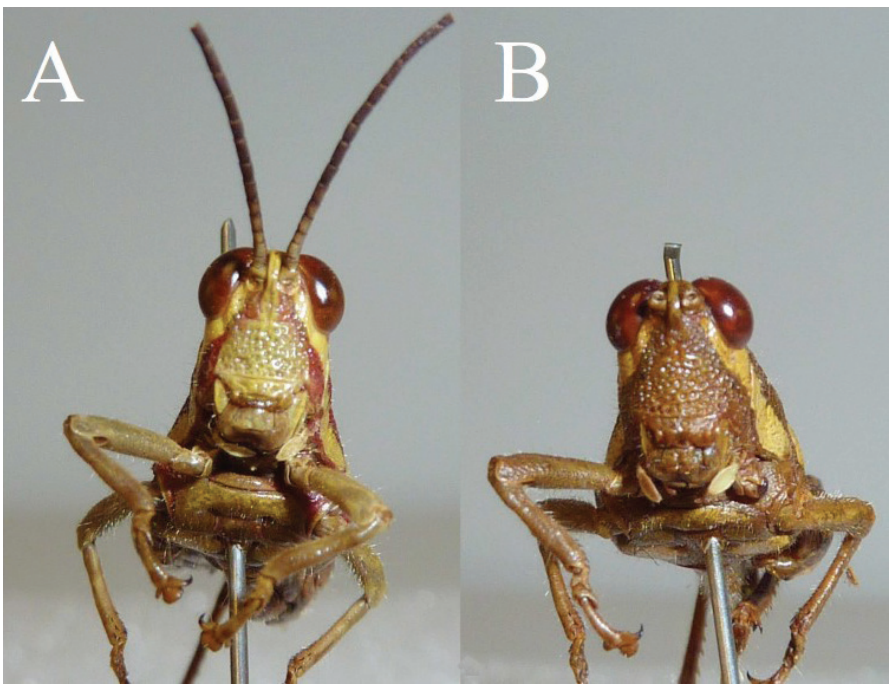

Fig. 2. Facial coloration of the female holotypes of A. Mopla rubra and B. M. guttata, showing the expanded terminal segments of the labial palps, and the difference in structure of the frontal ridges. The frontal ridge of guttata is almost devoid of medial sulcus, only a trace at the extreme ventral margin is apparent. In rubra there is a faint sulcus over the entire length. Photo credit: L.D.C. Fishpool.

knowledge, there has been no further record of this taxon since the original publication, and no male has been described.

We now report the capture of the first male of this genus. Its identification and description necessarily require reconsideration of Henry (1940)'s publication and of the type material.

\section{Methods}

Study area._Parambikulam Tiger Reserve (PKMTR) of Kerala is one of the richest wildernesses in the Western Ghats of India. PKMTR $\left(10^{\circ} 20^{\prime}-10^{\circ} 32^{\prime} \mathrm{N}, 76^{\circ} 35^{\prime}-76^{\circ} 5^{\prime} \mathrm{E}\right)$ is situated between Anamalai and Nelliyampathi hill ranges in the Palakkad District, Kerala, India. PKMTR has an area of $643.662 \mathrm{~km}^{2}$ and extends over an altitude ranging from $460 \mathrm{~m}$ to $1439 \mathrm{~m}$ asl. The vegetation types include evergreen, semi-evergreen, teak, moist deciduous, and riparian forests.

Grasshopper diversity of PKMTR was documented from 2015 to 2018. We collected and recorded the diversity of grasshoppers by using sweep netting and hand-picking of specimens. Standard Orthoptera taxonomy was followed using the Orthoptera Species File (Cigliano et al. 2018). The pinned specimens were deposited at the Kerala Forest Research Institute (KFRI) entomology museum.

The male Mopla specimen was relaxed in water to dissect the phallic complex. The phallic complex was extracted after treating the last abdominal segments with $10 \% \mathrm{KOH}$ that loosened the attached muscles and membranes. This procedure unfortunately destroyed the tergites and sternites of these segments, which are therefore missing from the final specimen. The components of the phallic complex were separated and sorted in vials with $70 \%$ alcohol. The phallic complex was then verified by CHFR. The complex was stained using acid fuchsin and differentiated in water. Dimensions were measured using a graticule eyepiece in the stereo microscope and a digital stage reading to $0.01 \mathrm{~mm}$ to move the pinned specimen under an appropriate magnification (between 6 and 50 times, depending on the size of the structure being measured). Drawings were made under the stereo microscope and edited using Photoshop CS5 (Adobe Systems Inc.). Specimens were imaged 
using digital camera DFC 295 attached to a Leica S8AP0 stereomicroscope and processed using software LAS V3.8. Image editing was accomplished using Adobe Photoshop CS4.

\section{Abbreviations of depositories:}

NHMUK Natural History Museum, London, United Kingdom. KFRI Kerala Forest Research Institute, Kerala, India.

\section{Results}

Comparison of M. guttata and M. rubra.-Henry's (1940) two specimens are almost identical superficially and obviously congeneric (Fig. 1A, B). When describing the second specimen as M. rubra, Henry (1940) wrote: "Very near to M. guttata, of which it will probably eventually be regarded as a subspecies; it differs from the latter, however, in so many minor points that I feel the only satisfactory course is to treat it as a full species". These "minor points" of difference were listed as follows: "Slightly smaller than M. guttata, with relatively shorter antennae; shorter and less well-developed tegmina, which are much more widely separated at their bases and are not so distinctly divided into two planes at vein $\mathrm{M}$; frontal ridge feebly constricted opposite antennal scrobes; below this point, irregularly sulcate to a point half-way to the clypeal suture; fastigium of vertex more evenly declivent, less tumescent than in M. guttata; puncturation of face, occiput, pronotum and pleurae less coarse than in the latter; pronotum with the angle of posterior margin rounded". Henry also noted differences in coloration, which are discussed later below.

We have examined and photographed the type specimens of both guttata and rubra (both in NHMUK), and have attempted to confirm these reported differences.

Size: Henry (1940) provided measurements of both specimens (Table 1), and there seems to be no reason to doubt his accuracy:

It is noteworthy, however, that Henry (1940) stressed that both body length measurements were uncertain, although he ultimately suggested the same value $(20 \mathrm{~mm})$ for both. All the other measurements show that guttata is $10-20 \%$ larger than rubra, except for length of the tegmen (T), where that of guttata is apparently $40 \%$ longer than rubra. The slightly larger size of guttata is apparent when the two types are compared (Fig. 3).

After normalizing for the difference in size of the two species by dividing each value by the length of the pronotum $(\mathrm{P})$, the ratio of guttata to rubra values is close to unity ( $\leq 10 \%$ difference) throughout, indicating that the relative sizes of different body parts are identical in the two specimens. Henry (1940) was therefore incorrect in stating that the antennae of rubra are "relatively shorter". The antennae are broken on both the types, and Henry's (1940) measurements cannot be checked. The exception to the above is the length of the tegmen (T), which is $20 \%$ longer in guttata even after normalization. Presumably this is the basis of Henry's (1940) statement that the tegmina of rubra are "shorter and less well-developed". We have checked this by recalculating the ratio $\mathrm{T} / \mathrm{P}$ from photographs of the two specimens, yielding new values of $\mathrm{T}=1.24 \mathrm{P}$ for guttata, and $\mathrm{T}=1.12 \mathrm{P}$ for rubra. This reduces the normalized guttata/rubra ratio to $1.24 / 1.12=1.11$, in line with that of all the other body measurements. We conclude, therefore, that Henry's (1940) tegmen measurement for guttata was somewhat too large, and that all the morphometric ratios of the two type specimens are within $10 \%$ of each other.
Table 1. Measurements of female Mopla guttata and M. rubra (Henry 1940).

\begin{tabular}{lcc}
\hline \multicolumn{1}{c}{ Measurements $(\mathrm{mm})$} & guttata female & rubra female \\
\hline Length of body & 20.0 & ca. 20.0 \\
Length of antenna & 13.0 & 11.0 \\
Width of head, across eyes & 4.5 & 4.1 \\
Length of pronotum & 7.0 & 6.0 \\
Greatest width of pronotum & 6.25 & 5.3 \\
Length of tegmen & 9.0 & 6.4 \\
Length of fore femur & 4.2 & 3.7 \\
Length of hind femur & 12.3 & 10.3 \\
\hline
\end{tabular}

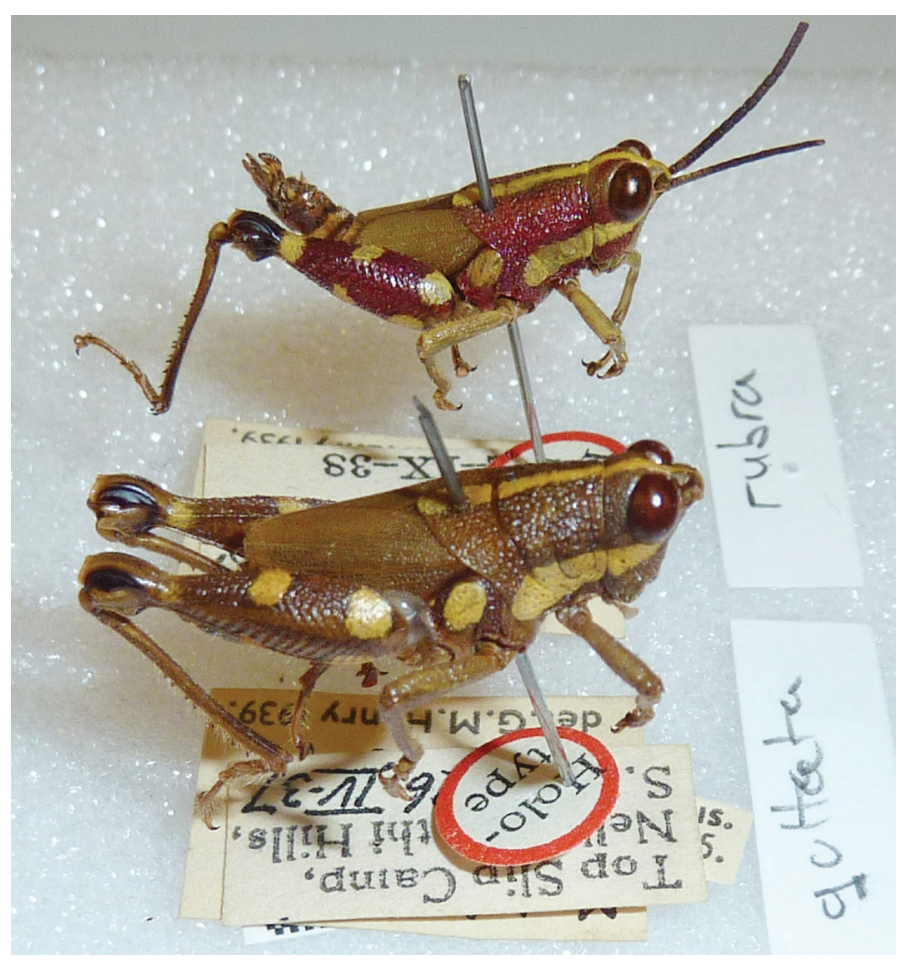

Fig. 3. Female holotypes of Mopla guttata (bottom) and of M. rubra (top), showing the slightly smaller size and distinctly redder ground coloration of M. rubra. Photo credit: L.D.C. Fishpool.

Separation of the wing bases: Henry's (1940) claim that $M$. rubra's wing bases are "much more widely separated" than those of M. guttata is unconvincing. In photographs of the types (Fig. 1), there seems to be merely a difference in the extent of overlap of the trailing edges of the tegmina, which could be influenced by the position of the tegmina or variation in their width.

Posterior angles of the pronotum: We traced the outlines of the pronotum in lateral photographs of the types and superimposed them. We found a slight difference as noted by Henry (1940), in that the posterior angle of the rubra type is indeed somewhat more smoothly rounded than that of guttata.

The remaining morphological criteria (slope and convexity of the fastigium, puncturation of the integument) cannot be examined critically in the available photographs.

In summary, the differences in morphology claimed by Henry (1940) are only partially supported on reexamination. The confirmed differences are slight, and alone are possibly insufficient for a specific separation, as Henry (1940) remarked. 
Biogeography of the Mopla species. -As mentioned above, the guttata and rubra type localities are both located in the Western Ghats and are relatively close to each other. Significantly, however, they are separated by a prominent geographical feature, the 30-40 $\mathrm{km}$ Palghat Gap (Myers et al. 2000), which is the only significant break in the chain of the Ghats. The Palghat Gap is known to be a major biogeographic barrier for numerous plant (Bahulikar et al. 2004, Apte et al. 2006) and vertebrate (Vidya et al. 2005, Gunawardene et al. 2007, Robin et al. 2010, Van Bocxlaer et al. 2012, Ram et al. 2015, Vijayakumar et al. 2016) species, and could very well interrupt gene flow between populations of flightless grasshoppers such as Mopla. It is therefore quite plausible that the slight differences seen between guttata and rubra derive from genetic differences and represent at least incipient speciation.

Is the newly captured male rubra or guttata?-Our male Mopla specimen was collected in the Anamalai Hills, only $3 \mathrm{~km}$ from the guttata type locality. If the Palghat Gap is suspected of being a boundary between the two populations of Mopla, this alone suggests that the male belongs to guttata. At least two morphological findings strengthen this hypothesis:

1. The detailed structure of the frontal ridge is very similar in our male and in the guttata female type (compare Figs 2 vs. 4). In both, the narrow rostral part of the ridge terminates just above the point where the medial ocellus would be expected, and at that point the ridge suddenly becomes sulcate for a very short distance immediately before its disappearance. This results in a small "fishtail" structure at the lower end of the frontal ridge, seen in both specimens. The faint suggestion of a longitudinal sulcus, seen in the holotype of rubra, is absent from both the female and the putative male of guttata.

2. The ratio T/P can be calculated from dorsal photos of the male as previously described for the female types. This produces a value of $\mathrm{T} / \mathrm{P}=1.28$, much closer to the female guttata value (1.24) than to the female rubra value (1.12). It is not unusual in grasshoppers for males to have relatively longer tegmina than females.
Henry (1940) further noted a difference in coloration between his two specimens. While both have a similar pattern of yellow markings on a brown background, in the female rubra he reported that much of the brown area was suffused with crimson (hence his specific name). This is not visible in the 80-year old type today, and has probably been lost by fading over time, but the rubra holotype is still distinctly more reddish brown than the olive-brown guttata holotype (Fig. 3). Significantly, however, the freshly caught male (Fig. 4) also shows no crimson coloration. This too supports the hypothesis that the male is guttata and not rubra, although sexual dimorphism in coloration is, of course, possible.

Henry (1940) also noted, but did not stress, a difference in facial coloration. Comparison of recent photographs of the holotypes (Fig. 2) shows that the frons of rubra is predominantly yellow, while that of guttata is dark brown. Our male has the latter coloration, as expected of guttata, at least in the absence of sexual dimorphism.

With a genus known from only three specimens, it is impossible to be sure of a specific determination as the range of intraspecific variation is unknown. However, all the available evidence (geographical, morphological, and coloration) suggest that we are dealing with the previously unknown male of Mopla guttata.

Material examined and depository--Allotype: Adult male (opposite sex to the holotype) (Fig. 4): INDIA: Kerala: Palakkad district: Parambikulam Tiger Reserve: Sungum range, coordinates $10^{\circ} 41^{\prime} 93.40^{\prime \prime} \mathrm{N}, 076^{\circ} 72^{\prime} 12.40^{\prime \prime E}$. 28.09.2016 (leg. D. Bhaskar). Specimen number OR0024 (KFRI).

Size: Table 2. Medium, L (length from fastigium to tip of sub genital plate) $=17.82 \mathrm{~mm}$.

Description of the male of $\mathrm{M}$. guttata.-Integument rugose, coarsely punctate, with numerous short white hairs. Antennae filiform, 22 segments, longer than head and pronotum together. Flagellum long and thick, black, flattened towards the tip with a light brownyellow terminal segment (Fig. 4). Head with rounded occiput, fastigium of the vertex triangular, wider at its base than long, extending slightly beyond the anterior margins of the antennal

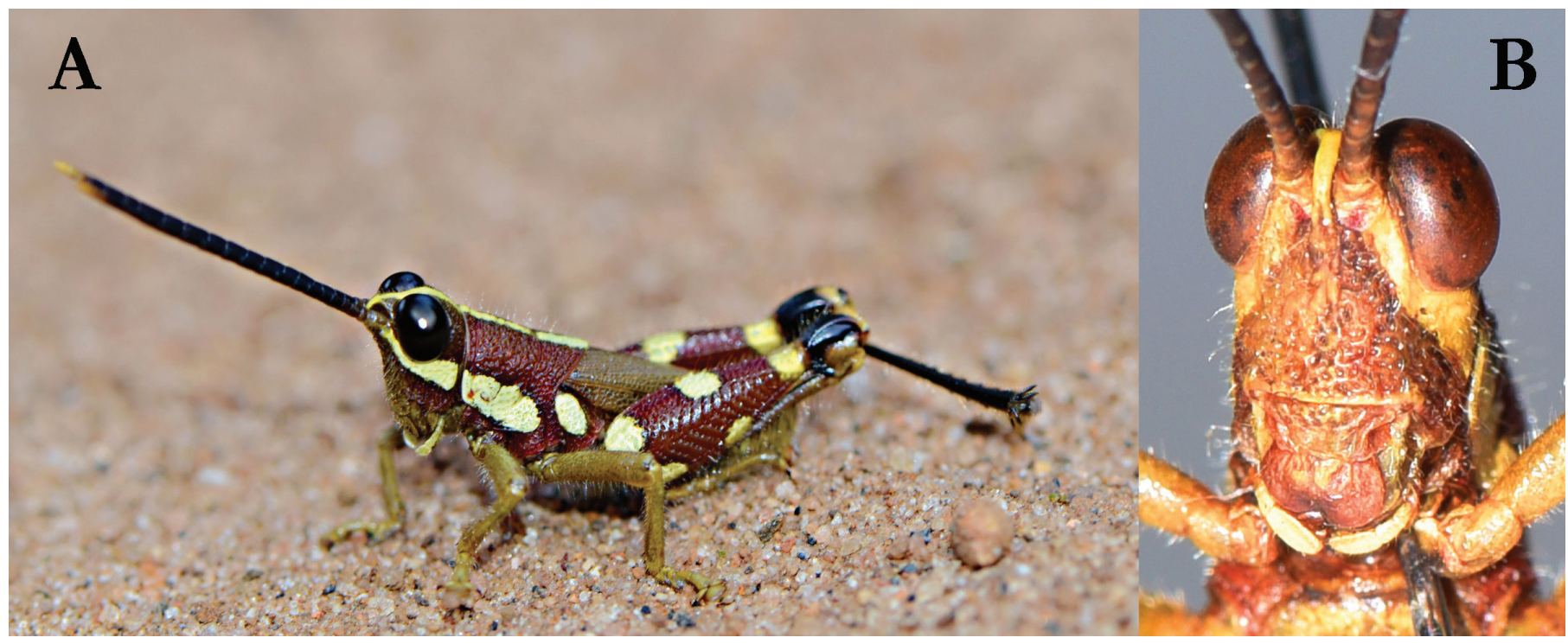

Fig. 4. Mopla guttata, male. A. Whole animal alive; the odd position of the right tibia is due to specimen being injured in capture. B. Oblique frontal view to show frontal ridge, for comparison with Fig. 2. Photo credit: D. Bhaskar and L.D.C. Fishpool. 
Table 2. Measurements of male Mopla guttata (specimen OR0024-KFRI).

\begin{tabular}{lcc}
\hline \multicolumn{1}{c}{ Character } & Code & Length (mm) \\
\hline Length from fastigium to tip of subgenital plate & $\mathrm{L}$ & 17.82 \\
Length of elytron & $\mathrm{E}$ & 5.51 \\
Length of antenna & $\mathrm{Ant}$ & 31.89 \\
Length of pronotum in the dorsal midline & $\mathrm{P}$ & 4.47 \\
Head and pronotum (combined length) & $\mathrm{H}+\mathrm{PN}$ & 7.43 \\
Length of hind femur & $\mathrm{F}$ & 12.64 \\
Depth of femur (the maximum width of the hind femur) & $\mathrm{FD}$ & 3.68 \\
Length of hind tibia & $\mathrm{Tib}$ & 10.21 \\
Length of the most proximal tarsal segment & $\mathrm{T} 1$ & 1.01 \\
Length of the second tarsal segment & $\mathrm{T} 2$ & 0.75 \\
Length of the distal tarsal segment & $\mathrm{T} 3$ & 2.49 \\
Total length of the three tarsal segments & $\mathrm{T} 1-\mathrm{T} 3$ & 4.25 \\
Foot formula ratio 0.23 (T1/T1-3) & & \\
0.17 (T2/T1-3) & & \\
0.58 (T3/T1-3) & & \\
\hline
\end{tabular}
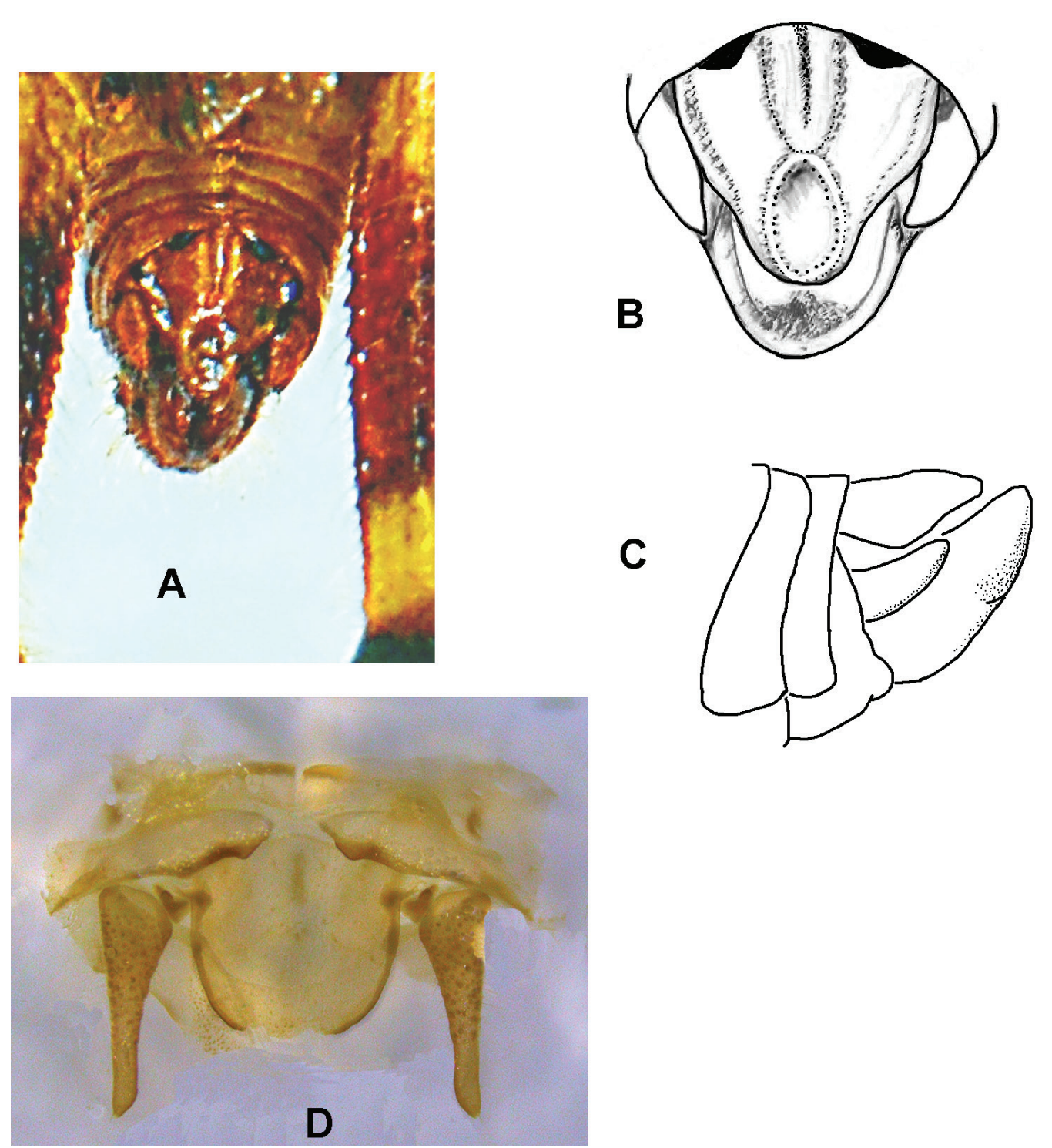
ocelli apparently obsolete. principal (most posterior) sulcus, and very weakly by one or two more anterior sulci. Prosternal tubercle short, vertical, slender and punctate, devoid of lateral or medial carinae. Fastigial foveolae absent. Frontal ridge lamelliformly compressed, developed only between the antennal sockets, obsolete below; extends as a very thin semicircular rostrum between the antennal scapes; anterior surface smooth, not sulcate, over most of its length, but minutely sulcate and divergent just at its ventral extremity (Fig. 4). Compound eyes large, globular and protuberant, interocular space narrow, less than width of antennal scape. Medial and lateral

Pronotum transversely rounded, medial carina scarcely visible, lateral carinae absent; front margin broadly rounded, hind margin obtuse-angulate, with a rounded tip. Metazona much shorter than prozona, its margins diverging strongly towards the rear. Disc of pronotum coarsely rugoso-punctate, deeply incised by the

Fig. 5. Male terminalia of Mopla guttata. A. Dorsal aspect of pinned specimen; B. Interpretive drawing of A; C. Lateral view; and D. Cleared preparation of abdominal tergites 10 and 11 . Note that the terminal lobe of the supraanal plate is missing; compare with A and $\mathbf{B}$. Furcula and the obliquely truncate cerci are clearly shown. 

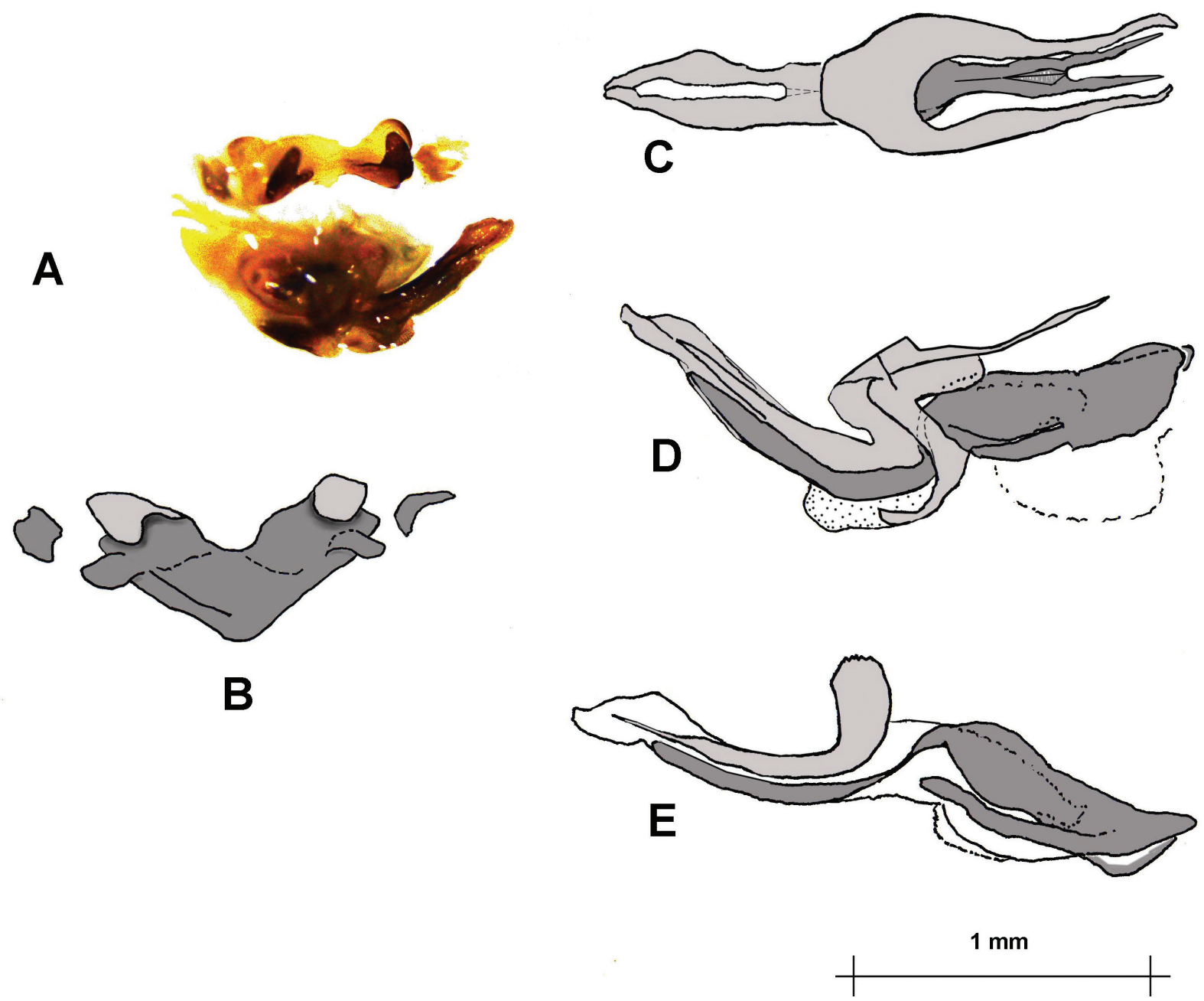

Fig. 6. Mopla guttata, phallic structures. A. Oblique posterior view of phallic complex before preparation and dissection; B. Epiphallus, anterior view; C. Dorsal and D. Lateral views of phallic complex with epiphallus, epiphallic, and ectophallic membranes removed; and E. Endophallus, arch sclerite, and ectophallic aedeagal valves, after removal of remaining ectophallic structures. In $\mathbf{C}-\mathbf{E}$ the endophallus is in a darker shading, the ectophallus in lighter shading. The broken line in D indicates the presumed position of the ejaculatory sac, missing from this preparation. Spermatophore sac stippled.

pointed. Brachypterous; tegmina overlap dorsally and extend only to $7^{\text {th }}$ abdominal tergite, with rounded tips. Wings: tegmen 5.51 $\mathrm{mm}$ long, olive brown in color. Legs: Pro- and mesothoracic legs stout, femora widened and nearly cylindrical, fore and middle tibiae rounded, with numerous small hairs, punctured. Hind femur stout, strongly rounded, thick, exceeds both abdomen and the elytra in length, coarsely punctured; dorsal and ventral longitudinal carinae weakly serrate. External face of femur with prominent chevron patterning marked by rows of strong punctures. Hind knees with medial dorsal tooth, ventral lobes slightly downwardly curved, pointed, but not spinous. Hind tibia stout with 8 external and 10 internal spines, inner spines are slightly longer than the external spines; external apical spine present. Hind tibia (10.21 $\mathrm{mm}) 2.40$ times as long as hind tarsus $(4.25 \mathrm{~mm})$. Third segment of hind tarsus longer than the first two segments together, foot formula $0.23,0.17,0.58$; arolia well developed. For the foot formula, the value for each tarsal segment is obtained by expressing its length as a percentage of the sum of the three tarsal segmental lengths; e.g., the value for $\mathrm{T} 2$ is $\mathrm{T} 2 /(\mathrm{T} 1+\mathrm{T} 2+\mathrm{T} 3)$. This formulation allows the feet of different species of different sizes to be compared with each other.
Abdomen: Short, conical and compressed, tenth abdominal tergite divided, with a weak furcula (Fig. 5). Supra-anal plate roughly triangular, with a rounded tip. Male cerci fairly short, straight, tapering to an obliquely truncate tip (Fig. 5). Male subgenital plate rather short, apex smoothly rounded in lateral view.

Phallic complex: (Fig. 6). Elongate and slender, aedeagus equal in length to the more proximal parts of the phallus. Epiphallus: bridge shaped, broad, undivided medially, with short hooked ancorae and large tapering lobe-shaped lophi that are curved over at their tips. Lateral lobes weakly differentiated. Oval sclerites present, of irregular shape. Ectophallic apodemes long and slender, tapering, more or less parallel; zygoma rounded, rami slender, running rearwards at their tips, and giving rise to an extensive ectophallic sheath surrounding the dorsal aedeagal valves. Arch sclerite large, supporting long spatulate dorsal aedeagal valves that exceed the ventral valves in length. Endophallus slender, gonopore processes present and elongate, extending ventrally almost to the flexure. Flexure slender, ventral aedeagal valves tapering but not pointed. Endophallic apodemes small and narrow, not inflected laterally. Ejaculatory sac apparently 
lost in dissection, spermatophore sac lies ventrally, between and below the ventral aedeagal valves.

Biology.-Practically nothing is known of the way of life of this genus. The male specimen was caught on low bushes at a forest verge with predominantly herbaceous vegetation. Henry's (1940) holotypes were caught "in rain-forest", with no further details provided. The hind foot formula, with a short second tarsal joint, suggests a life on herbaceous plants rather than an arboreal one, and the large arolia rules out a terrestrial way of life.

\section{Discussion}

Henry (1940) tentatively placed Mopla in the Catantopinae; his reservations were based on the lack of a precise diagnosis of this subfamily. Dirsh (1961) later described the Catantopinae as a subfamily with no exclusive diagnosis; historically the subfamily has been used as a depository for forms that do not fit the criteria for other Old-World subfamilies (Akite and Rowell 2013). The present description shows that Mopla has a typically catantopine phallic complex with a long sheathed aedeagus, the sheath being derived from the ectophallus, very reminiscent of that seen in e.g., the African Serpusiae (Rowell et al. 2018).

Henry (1940) mentioned a discussion he had with Uvarov regarding an alleged similarity of Mopla to Neotropical grasshoppers and its differences from other Old-World grasshoppers. Some characters of Mopla, especially the structure of the head and the unique bold spotting and banding all over the body including on the femora, apparently caused Henry to perceive a faint affinity of this genus to the Neotropical group Tropinoti. It is not clear what characters could have led Uvarov or Henry to this speculation; Tropinotus Serville 1831 is now considered a junior synonym of Xyleus, a large macropterous Romaleinae savanna grasshopper, completely different from Mopla in both habitus and ecology. Mopla seems to be well placed in the Catantopinae as currently understood and has morphology typical of tropical forest light-gap species worldwide, with brightly contrasting coloration, prominent eyes, and diminished flight ability (Rowell 1978).

\section{Acknowledgements}

We are thankful to the Director, Dr. Sreejith KA, Dr. Sajeev TV, (scientists) and the scientific community of Kerala Forest Research Institute (KFRI) for facilitating the study. Financial support from the Orthoptera Species File (OSF) to DB made the visit to European museums possible for verifying the type specimens. We are thankful to Maria Marta Cigliano and Holger Braun of the OSF for their wholehearted support during the study. We especially thank Dr. Judith Marshall of the NHMUK for access to the type specimens of Mopla, and Dr. L.C.D. Fishpool for taking photographs of them at our request. We acknowledge the Parambikulam Tiger Conservation Foundation of Kerala Forest and Wildlife Department along with our field assistants, Bagyaraj and Sreenivasan. Thanks to Mr. Subin KK and Mr. Bharath for assistance with Photoshop. We acknowledge the skills of Mr. Shiju (driver KFRI) in driving through the forests.

\section{References}

Akite P, Rowell CHF (2013) Oshwea dubiosa rediscovered in Uganda. Journal of Orthoptera Research 22: 45-49. https://doi. org/10.1665/034.022.0107
Apte GS, Bahulikar RA, Kulkarni RS, Lagu MD, Kulkarni BG, Suresh HS, Rao PSN, Gupta VS (2006) Genetic diversity analysis in Gaultheria fragrantissima Wall. (Ericaceae) from the two biodiversity hotspots in India using ISSR markers. Current Science 91: 1634-1640.

Bahulikar RA, Lagu MD, Kulkarni BG, Pandit SS, Suresh HS, Rao MKV, Ranjekar PK, Gupta VS (2004) Genetic diversity among spatially isolated populations of Eurya nitida Korth. (Theaceae) based on intersimple sequence repeats. Current Science 86: 824-831.

Bhaskar D, Easa PS, Hochkirch A (2018) Digitalisation of Indian Orthoptera types deposited in British Natural History Museum, London (NHM UK) and a checklist to Orthoptera of Kerala, India. Metaleptea 38: 18-23.

Chandra K, Gupta SK, Shoshodia MS (2010) A checklist of Orthoptera (Insecta) of India. Zoological Survey of India (M.P.), 1-57.

Cigliano MM, Braun H, Eades DC, Otte D (2018) Orthoptera Species File. Version 5.0/5.0. http://orthoptera.speciesfile.org [accessed Nov 2018]

Dirsh VM (1961) A preliminary revision of the families and subfamilies of Acridoidea (Orthoptera, Insecta). Bulletin of the British Museum of Natural History (Entomology) 10: 349-419. https://doi.org/10.5962/ bhl.part. 16264

Gunawardene NR, Dulip Daniels AE, Gunatilleke IAUN, Gunatilleke CVS, Karunakaran PV, Geetha Nayak K, Prasad S, Puyravaud P, Ramesh BR, Subramanian KA, Vasanthy G (2007) A brief overview of the Western Ghats-Sri Lanka biodiversity hotspot. Current Science 93: $1567-1572$.

Henry GM (1940) New and little known South Indian Acrididae (Orthoptera). Transactions of the Royal Entomological Society of London 90: 497-540. https://doi.org/10.1111/j.1365-2311.1940.tb01033.x

Nayeem R, Usmani K (2012) Taxonomy and field observations of grasshopper and locust fauna (Orthoptera: Acridoidea) of Jharkhand, India. Munis Entomology and Zoology 7: 391-417.

Myers N, Mittermeier RA, Mittermeier CG, da Fonseca GAB, Kent J (2000) Biodiversity hotspots for con-servation priorities. Nature 403: 853857. https://doi.org/10.1038/35002501

Priya AV, Narendran TC (2003) A key and a checklist of the genera of shorthorned grasshoppers (Orthoptera: Acridoidea) of Kerala. Entomon 28: 223-230.

Ram MS, Marne M, Gaur A, Kumara HN, Singh M, Kumar A, Umapathy G (2015) Pre-historic and recent vicariance events shape genetic structure and diversity in endangered lion-tailed macaque in the Western Ghats: Implications for conservation. PLoS ONE 10: e0142597. https://doi.org/10.1371/journal.pone.0142597

Robin VV, Sinha A, Ramakrishnan U (2010) Ancient geographical gaps and paleo-climate shape the phylogeography of an endemic bird in the sky-islands of Southern India. PLoS ONE 5: e13321. https://doi. org/10.1371/journal.pone.0013321

Rowell CHF (1978) Food-plant specificity in neotropical rain forest acridids. Entomologia Experimentalis et Applicata 24: 651-662.

Rowell CHF, Jago ND, Hemp C (2018) Revision of Aresceutica (Orthoptera: Acrididae: Catantopinae) with comments on related genera. Journal of Orthoptera Research 27: 107-118.

Tandon SK, Hazra AK (1998) Orthoptera. In: Faunal Diversity in India. ENVIS Centre, Zoological Survey of India, Calcutta, 184-188.

Van Bocxlaer I, Biju SD, Willaert B, Giri VB, Shouche YS, Bossuyt F (2012) Mountain-associated clade endemism in an ancient frog family (Nyctibatrachidae) on the Indian subcontinent. Molecular Phylogenetics and Evolution 62: 839-847. https://doi.org/10.1016/j. ympev.2011.11.027

Vidya TNC, Fernando P, Melnick DJ, Sukumar R (2005) Population differentiation within and among Asian elephant (Elephas maximus) populations in southern India. Heredity 94: 71-80. https://doi. org/10.1038/sj.hdy. 6800568

Vijayakumar SP, Menezes RC, Jayarajan A, Shanker K (2016) Glaciations, gradients, and geography: multiple drivers of diversification of bushfrogsin the Western Ghats Escarpment. Proceedings of the Royal Society B: Biological Sciences 283(1836): 20161011. https:// doi.org/10.1098/rspb.2016.1011 